\title{
A religiosidade na educạạão da juventude
}

\section{Religiousity in youth education}

\author{
Gilberto Tomazi*
}

Recebido: 29/06/2019. Aprovado:16/08/2019.

Resumo: Os jovens são sujeitos da história, mas, também, resultado de processos de desenvolvimento sociocultural e histórico, nos quais eles interagem, modificando-os e deixando-se transformar por eles. A mudança de época em que estamos vivendo inclui costumes, tradições, culturas, localizações e religiosidades que, herdados e ressignificados pelos jovens, se juntam numa complexa dinâmica de educação e construção histórica.

Este artigo faz uma crítica aos atuais processos de educação da juventude estruturados numa visão tecnicista e mercadológica e visa contribuir com a reflexão a respeito da importância da religiosidade no processo de formação integral e pastoral dos jovens, na perspectiva de uma vida melhor, e de uma sociedade mais solidária, includente, democrática, respeitosa e pacífica.

Palavras-chave: Juventude. Educação. Religiosidade.

Abstract: Young people are subjects of history, but also the result of processes of socio-cultural and historical development in which they interact, modifying them and being transformed by them. The changing times in which we are living include customs, traditions, cultures, locations, and religions that, inherited and resignified by young people, come together in a complex dynamic of education and historical construction.

This article is a critique of the current processes of youth education structured in a technicist and marketing perspective, and aims to contribute to the reflection on the importance of religiosity in the process of integral and pastoral formation of young people, from the perspective of a better life, of a more solidary, inclusive, democratic, respectful and peaceful society.

Keywords: Youth. Education. Religiousity.

* Doutor em Ciências da Religião (Pontifícia Universidade Católica, São Paulo, 2013). Mestre em Ciências da Religião (Pontifícia Universidade Católica, São Paulo, 2005). Especialista em Ensino Religioso (UNOESC, Videira, 2000). Bacharel em Teologia (ITESC, Florianópolis, 1995). Licenciatura em Pedagogia (UNIARP, Caçador, 1991).

E-mail: giltom3@gmail.com 


\section{Introdução}

Os jovens são sujeitos da história, mas, também, resultado de todo um processo de desenvolvimento sociocultural e histórico, no qual eles interagem, modificando-o e sendo modificados por ele. Costumes, tradições, culturas, localizações e religiosidades de jovens se juntam numa complexa dinâmica de educação e construção histórica.

A religiosidade na educação de crianças, adolescentes e jovens reaparece na atualidade como uma referência da busca de novos sentidos e novos paradigmas. A religiosidade emerge hoje como uma motivação profunda que move boa parte dos jovens e dinamiza suas ações na busca de uma vida melhor. A religiosidade é um dos elementos que dá sustentação a iniciativas de educação popular na perspectiva da formação integral da juventude. Ela ajuda na mobilização e articulação da juventude, a partir de dentro da complexa trama da vida, tecida sob a influência de muitos fatores, num processo de bricolagem, fazendo de pequenas práticas, impulsionadas pela sensibilidade solidária, uma abertura para o novo, o possível, o realizável e o utópico.

É em meio a um amplo emaranhado de conflitos, diálogos, agrupamentos e participações sociais que jovens se percebem atores sociais e protagonistas, também, de uma nova sociedade que, por sua vez, significa a continuidade desta mesma sociedade, antecipando-lhe, porém, o futuro possível e sonhado. Essa perspectiva que visa a construir uma nova sociedade não segue um único caminho, não se ocupa de uma ideologia, não insiste em uma forma de organização centralizada, não tem um projeto detalhadamente planejado; comporta a dimensão religiosa que incorpora a perspectiva utópica que se materializa em pequenas iniciativas de mudanças, que podem passar despercebidas, pois, em geral, são lentas, ambíguas, virtuais, pouco planejadas e sistematizadas. É nos pequenos grupos que acontece a integração social e um processo de socialização maior, de superação do individualismo e de aprendizagem e operacionalização no exercício do poder. Nesse sentido, elementos da tradição, da cultura, da história são importantes para o processo de educação integral dos jovens.

No Brasil dos últimos quinhentos anos, houve uma insatisfação ampla e permanente das pessoas e, especialmente, dos mais pobres e dos jovens, em relação à realidade vigente. $\mathrm{Na}$ atualidade, essa insatisfação vem acompanhada de uma descrença nas formas de política, no sistema 
jurídico e no sistema econômico estabelecidos e hegemônicos como solução para os problemas sociais. Podemos perceber que grande parte dos jovens hoje não é apática e acomodada, mas, sim, capaz de procurar contribuir nos processos de solução dos problemas sociais e, também, de resistir, de combater instituições autoritárias, processos sociais e meios de comunicação degradantes, alienantes e violentos, na busca de alternativas possíveis, de um mundo melhor.

Este artigo visa contribuir com a reflexão a respeito da importância da religiosidade na educação e formação integral dos jovens, na perspectiva de um mundo melhor, mais solidário, includente, democrático, respeitoso e pacífico.

\section{A juventude: novos paradigmas}

Ao falar de novos paradigmas, não significa que tenhamos a pretensão de romper com as teorias já constituídas ou com os caminhos já abertos para a compreensão da juventude, mas, sim, perceber a insuficiência, os conflitos e contradições inerentes às teorias e aos métodos por elas percorridos, a fim de se afirmar como campo científico. Em primeiro lugar, ao referir-se à juventude, é necessário considerar que tanto o pesquisador quando o objeto de seu estudo, são dinâmicos, sujeitos participantes de processos históricos também dinâmicos, conflitivos, ambíguos, em processo permanente de transformação. Em segundo lugar, precisamos considerar que toda a história do "homo sapiens" contemplou e absorveu a necessidade e o desejo de buscar mais conhecimentos, de obter mais certezas, de construir melhores explicações da realidade e, para isso, lançou mão de crenças, utopias e a ideia do devir, como possibilidades de superação de uma dada realidade e como horizonte de sentido. As sociedades procuram viver o presente, projetando-se para o futuro e obtendo lições do passado que, por sua vez, é ressignificado constantemente, no embate entre o que está sendo realizado com aquilo que está dado. Em terceiro lugar, pode-se dizer que os novos paradigmas não são apenas teóricos e metodológicos, são também realidades e práticas constituídas, cuja "carne ainda não se fez verbo", ou seja, cujas elaborações científicas se fazem ainda ausentes ou, pelo menos, insuficientes.

Pode-se considerar que, na história da humanidade, ao menos quatro paradigmas se destacaram sobremaneira. O primeiro era aquele em que grande parte do tempo, no cotidiano da vida, era dedicado ao lazer, à espiritualidade e à convivência entre familiares ou membros de 
uma mesma aldeia. Nesse paradigma, o trabalho estressante era reduzido ao máximo, trabalhava-se basicamente apenas o necessário para garantir a alimentação e a moradia. Um segundo paradigma foi o do trabalho cansativo, da guerra e vontade de poder. Se o paradigma anterior era de quatro ou cinco horas de trabalho diários, esse alcançou quinze ou mais horas, agora era preciso acumular riqueza e ter segurança de que ela não seria desapropriada ou extorquida por outrem. Fizeram-se necessários grandes exércitos e outras instituições, capazes de garantir a concentração do poder político nas mãos dos donos do capital, e um amplo processo de desenvolvimento industrial. A necessidade de poder e riqueza crescentes se sobrepôs a outras necessidades tidas então por secundárias, tais como as necessidades culturais e religiosas. Este paradigma culminou no materialismo, na competição e no individualismo. A sociedade do conhecimento, da informação e da comunicação passou a ser o terceiro paradigma, também chamado de pós-moderno ou pós-materialista. Se é verdade que este paradigma já contagiou uma significativa parcela da humanidade, também é verdade que, tanto quanto os demais, ele comporta contradições e deixa lacunas e vazios tais como a busca da espiritualidade e de sentido, a realização do ser, a sabedoria, a paz, a erradicação da miséria e das doenças, o equilíbrio entre desejos e necessidades, a busca de um mundo includente, democrático, solidário e ecologicamente sustentável, culturalmente plural, entre outras. É justamente a partir dessas lacunas e vazios que se abrem as portas para a emergência do quarto paradigma. Não que este exclua o anterior, mas vem fazendo parte de uma "revolução silenciosa" cujos partidários, mormente jovens, parecem aumentar dia-a-dia. É nessa percepção que René Dreifuss, reconhecendo que estamos numa "época das perplexidades", afirma:

O mundo vai sendo restaurado e renovado com uma ampla recomposição de forças, onde a mudança parece não somente possivel e desejável, mas necessária e legítima. Tudo indica que começamos a enfrentar uma constante desconstrução e reconstrução de estruturas e práticas políticas, de instituições e sistemas, na procura de novas referências. ${ }^{1}$

Cada momento histórico e os próprios ramos da ciência incorporam um conjunto de crenças, valores, formas de trabalhar, visões do ser humano e do mundo, ora reconhecidos, ora quebrados pela comunidade científica, acontecendo assim revoluções permanentes, donde emergem

1 DREIFUSS, R. A Época das Perplexidades. 2. ed. Petrópolis: Vozes, 1997. p. 336s. 
novos paradigmas. Thomas Kuhn, físico que tornou o termo conhecido mundialmente, afirmou que, na ciência, um paradigma surge quando é difícil envolver novos dados em velhas teorias. ${ }^{2}$

É dentro desse quarto paradigma que vemos emergir parte considerável dos jovens da atualidade. A juventude vem-se tornando algo concreto, vivo, e não apenas uma convenção social, uma criação dos costumes, um produto literário ou um estado de espírito. Ela deixa de ser apenas um lugar e se torna um sujeito histórico. Ela não deixa de ser um mito, porém a deusa Juventa não se passa apenas na cabeça; ela ousa descer para o corpo todo e se torna movimento, rito, história, deixando assim de ser apenas uma abstração ou uma teoria voltada para um passado remoto. Já não se pode mais falar de juventude, apenas num sentido mítico. Faz-se necessário reconhecê-la em sua práxis e em suas relações. Hoje a juventude não é mais considerada uma deusa, intocável, sagrada. Ela é feita de humanos e, por isso, carrega consigo a semente de contradição, de antagonismo, de ambiguidades, presentes em qualquer ser humano e, também, da sociedade como um todo.

No novo paradigma juvenil, não habitam mais as grandes teorias ou ideologias, sejam elas socialistas, estudantis, populares ou liberais; agora eles preferem estabelecer relações e lutas mais conjunturais e setoriais, por causa de preferências sexuais, de defesa do meio ambiente, de direitos das mulheres, por causa do cuidado do corpo, para prestar serviços de solidariedade, pela ética e pela paz. O nível macroestrutural é importante, todavia é o cotidiano da vida que merece atenção especial desse novo paradigma. O risco desse novo paradigma é reduzir o agir a pequenos grupos desarticulados e a um enfoque exclusivamente local e centrado no indivíduo. Michel Foucault já assinalou o fato de que "vivemos atualmente o desaparecimento do 'grande escritor' do intelectual geral, 'universal', os 'específicos' tomam espaço," porém ele afirma que com isso ganhou-se uma consciência muito mais concreta e imediata das lutas. ${ }^{3}$

Ao que tudo indica, as perspectivas atuais sugerem que é preciso que o jovem seja ético e responsável, se quiser ver um dia uma mudança mais ampla nas estruturas sociais, e não o contrário. O tempo futuro se parece muito distante para preocupar os jovens desse novo paradigma.

2 KUHN, Thomas S. A Estrutura das Revoluções Científicas. São Paulo: Perspectiva, 1962. p. 60.

3 FOUCAULT, M. Microfísica do poder. 5. ed. Rio de Janeiro: Graal, 1985. p. 9s. 
É o hoje que precisa ser pensado devidamente e construído, a fim de que valha a pena viver também o tempo presente. Conforme Leslie Serna, pode-se afirmar que hoje prefere-se participar de ações com coordenações transitórias e não centralizadas, que respeitem a heterogeneidade juvenil e o indivíduo, agora mais autônomo, sem grande interesse em representar uma classe de jovens e também sem anular o indivíduo em prol de um coletivo massificado. Hoje as redes de jovens crescem na medida em que se fazem facilitadoras da vida e não centralizadoras na tomada de decisões. ${ }^{4}$

\section{A religião nos processos educativos da juventude}

As crianças, os adolescentes e os jovens não levam para a escola apenas a sua herança cultural e religiosa familiar, mas também um mundo de dúvidas e questões que encontram por aí, na internet, na televisão e nas ruas desse mundo, que é também religioso, em processo de globalização. Se a escola não oferecer respostas, outras instituições, talvez menos preparadas, o fá-lo-ão. Um elemento constitutivo ou indispensável de uma nação que se entende como democrática e plural, é abrir seus processos educacionais à população, ouvindo e dialogando sobre os seus interesses, sua história, sua cultura e suas tradições.

Para evitar a intolerância, o fanatismo, o radicalismo, o fundamentalismo e o proselitismo religioso, é imprescindível cultivar o respeito mútuo entre os seres humanos e entre as religiões. As sementes do respeito, do diálogo e da alteridade, quando semeadas ainda na infância, também pela escola, ajudam os adolescentes e jovens a, além de conhecerem melhor sua identidade, enfrentar e posicionar-se mais conscientemente diante de grandes desafios que a humanidade enfrenta. Ao levar em conta a necessidade da formação integral do ser humano, a escola não pode menosprezar a sua dimensão religiosa. À escola cabe, não apenas formar profissionais técnicos, mas, também, contemplar a formação integral do ser humano.

A história, a cultura, as ciências e tudo existe ou venha a existir tem, na religião, sentido, porque são integradas numa ordem cósmica. A religião expressa sua eficácia por meio de esquemas de pensamento que se inscrevem nas consciências individuais e nelas se incorporam como se fossem naturais, transformando-se em hábitos. Pode-se afirmar que hoje

$4 \quad$ SERNA, L. Globalización y participación juvenil. México: Rev. Est. Juventud, 1998. p. 50. 
os meios de comunicação se apresentam como quem assumiu a função que antes era própria da religião, dar sentido e ordem aos acontecimentos. Todavia, cada vez mais esses meios foram submetidos a uma lógica comercial inimiga da palavra, da verdade e dos significados reais da vida. Na Exortação Apostólica Sobre a chamada à santidade no mundo atual o Papa Francisco destaca que

Hoje em dia, tornou-se particularmente necessária a capacidade de discernimento, porque a vida atual oferece enormes possibilidades de ação e distração, sendo-nos apresentadas pelo mundo como se fossem todas válidas e boas. Todos, mas especialmente os jovens, estão sujeitos a um zapping constante. É possivel navegar simultaneamente em dois ou três visores e interagir ao mesmo tempo em diferentes cenários virtuais. Sem a sapiencia do discernimento, podemos facilmente transformar-nos em marionetes à mercê das tendências da ocasião. ${ }^{5}$

Segundo Ana L. Modesto, a religião exerce uma função integradora por excelência: "ela reúne todas as atividades do ser humano sob a sombra de uma finalidade comum. A religião possibilita a existência de sentimentos coletivos e, simultaneamente, o indivíduo, o sentimento de si.[...] A religião atua com eficácia, possibilitando a reconstituição de uma unidade perdida, tanto em nível individual, como também de grupos sociais. ${ }^{\prime 6}$ Ela aparece como integradora, produtora de conhecimento e de sentido para a existência, todavia tem sido sistematicamente relativizada e, até mesmo, excluída dos sistemas escolares. Apenas os sistemas de ensino mais atualizados é que abriram espaços para que, de fato, o conhecimento religioso fosse reconhecido como conhecimento científico e, portanto, de interesse público e relevante à sociedade.

A busca do transcendente negada, durante muito tempo, pelo positivismo tecnicista, está sendo resgatada como aspecto importante na formação do ser humano. Compreender as pessoas como números ou como peças de uma engrenagem já não é mais suportável. A religiosidade que fora apresentada como fadada ao desaparecimento, com a ascensão da modernidade, é ou volta a ser uma dimensão que orienta e faz o ser humano sentir-se gente, que o torna solidário e respeitado em sua inviolável dignidade. $\mathrm{O}$ sentido e a importância da dimensão religiosa

5 FRANCISCO. Exortação Apostólica Gaudete et Exsultate. Brasília: CNBB, 2018. n. 167.

6 Apud: DAYRELL, J. Múltiplos olhares sobre educação e cultura. Belo Horizonte: UFMG, 1996. p. 80s. 
da vida humana já não podem ser negados, nem pela ciência e nem pela política, sob a pena de impossibilitar um salto de qualidade no resgate do ser humano como totalidade e integridade.

A partir de todos e de cada um, emergem forças ou energias destrutivas ou vivificadoras, capazes de criar e recriar vidas, nascer e renascer seres. Ninguém existe só, mas co-existe, com-vive. A planta depende da lua, a lua da terra, a terra do sol, o sol do galo que canta e agradece... Cada ser humano, interagindo com os demais seres, precisa aprender a fazer o seu meio e contribuir na construção do seu mundo, e o de toda uma coletividade, de maneira criativa, responsável e conforme os grandes consensos humanos, tais como as leis universais e as regras de ouro, que geralmente são extraídas do que é comum entre os diferentes textos sagrados e tradições humanas. Edgar Morin apresenta o ser humano de maneira integral e em relação com todo o universo: "estamos, a um só tempo, dentro e fora da natureza. Somos seres, simultaneamente, cósmicos, físicos, biológicos, culturais, espirituais..."7

\section{Socialização de conhecimentos religiosos para a vida em sociedade}

O conhecimento religioso, revelado ou não, é parte do conhecimento humano e, por isso, pode estar entre os fundamentos dos processos educacionais. A escola é um espaço de construção de conhecimentos e, principalmente, de socialização dos conhecimentos historicamente produzidos e acumulados. Como todo o conhecimento humano é sempre patrimônio da humanidade, o conhecimento religioso deve, também, estar disponível a todos os que dele queiram ter acesso.

A tarefa de buscar fundamentos para a educação de adolescentes e jovens remete às questões do fundamento do conhecimento humano. Sendo um conhecimento humano, porque a experiência religiosa não poderia ser objeto do conhecimento científico? A escola é um espaço de construção de conhecimentos e, principalmente, de socialização dos conhecimentos histórica e culturalmente produzidos e acumulados. Como todo o conhecimento humano é sempre patrimônio da humanidade, o conhecimento religioso deve, também, estar disponível a todos os que dele queiram ter acesso.

7 MORIN, E. A cabeça bem-feita: repensar a reforma, reformar o pensamento. Rio de Janeiro: Bertrand Brasil, 2000. p. 38. 
Durante séculos de história, a religião foi referência para as pessoas, mas o racionalismo, que marca a modernidade, tentou negá-la, apregoando a supremacia da ciência, da técnica e da comunicação. Isso forjou o ser humano atual, fragmentado, insatisfeito, inseguro, inquieto, desconfiado... Agora, mais do que nunca, procura respostas que lhe deem sentido à vida, que lhe permitam transcender a este mundo e acreditar em algo mais. O ser humano recoloca essas questões, tentando reorientar o próprio pensamento sobre a vida humana e a sua finalidade. O fenômeno religioso vem suscitando o interesse de pesquisadores e instituições. A busca do sentido da vida rompe com as certezas da razão instrumental e coloca novas questões que nem sempre a análise científica consegue incorporar.

É aí que o diálogo entre teologia, filosofia, antropologia, cosmologia e ciências da religião, entre outras, pode-se tornar eminentemente fecundo. A partir desse diálogo pode-se fornecer, com mais propriedade, um conjunto de noções sistemáticas sobre a origem e a história do ser humano e, também, explicar fenômenos da natureza, hábitos de animais, influências meteorológicas, movimentos do universo, bem como procurar explicar as imagens de mundo que a sociedade produz, orientando e situando o ser humano em relação ao seu meio. Deste diálogo pode-se apreender conexões e estabelecer correlações cada vez mais precisas entre fatores culturais, religiosos, míticos, arqueológicos, cosmogônicos, cosmogênicos, hierofânicos, biológicos e sociais no processo de "hominização".

Muitos povos elaboraram mitos para explicar a origem do mundo e do homem, para dar sentido e para explicar o tempo presente. O sol, a lua, os ancestrais, os astros, as divindades e mesmo outros seres animados ou inanimados tornaram-se referenciais da vida de povos e culturas. Atribuições morais, éticas e religiosas são depositadas ou cristalizadas às "forças" que transcendem a natureza, que se situam no mistério, no além da capacidade de apreensão humana. Os mitos, normalmente, imbricam cultura, religião e natureza de tal forma que o ser humano aparece como resultado dessa trindade, resultado, esse, que não significa a negação do ser humano enquanto "destinatário" e "sujeito" histórico.

A partir desse diálogo, emerge o olhar científico para o cotidiano e a cultura. Cotidiano, porque contextual: de que valeria estudar o ser humano senão porque o tempo presente se impõe cheio de contradições e por isso de possibilidades? E, cultural porque eminentemente criador. 
É na cultura que se revela o potencial transformador e da tradição de um povo. A cultura de um povo se processa a partir de sua cosmologia e esta, dificilmente, poderá ser apreendida suficientemente pela ciência. Logo, cultura e mistério se aproximam.

Para Leonardo Boff, faz-se necessário um olhar em três dimensões: para o universo, para a terra e para nós mesmos. Ele afirma que "conhecendo um pouco da história do universo e da Terra, estamos conhecendo a nós mesmos e a nossa ancestralidade". ${ }^{8}$ Ao mesmo tempo em que tendemos a divagar no universo, voltamo-nos para a possibilidade de sínteses, que nos deem certezas. Fritjof Capra, observando a cosmologia oriental, percebe que

a característica mais importante da visão oriental do mundo é a consciência da unidade e da inter-relação de todas as coisas e eventos, a experiência de todos os fenômenos do mundo como manifestações de uma unidade básica. Todas as coisas são encaradas como partes interdependentes e inseparáveis do todo cósmico. ${ }^{9}$

O ser humano, sujeito da história, é guiado segundo os princípios que o transcendem. O reconhecimento da dimensão religiosa do ser humano e das suas experiências em torno de Deus ou de divindades volta a ser, na atualidade, um acréscimo e não uma incógnita ou uma ilusão da humanidade. Ele permite e reinaugura a possibilidade da receptividade, da reciprocidade, da alteridade, da subjetividade e da intimidade entre as pessoas consigo mesmas, com seus ancestrais, com suas origens e com seu Criador. Permite, também, uma conversão que, segundo Angel Castiñeira, consiste na

a passagem de uma razão que capta e explica para uma razão que escuta e acolhe, de uma vontade que domina para uma vontade que aceita e reconhece, de uma liberdade que escolhe e dispõe para uma liberdade que se entrega. ${ }^{10}$

A religiosidade volta a ter sentido não como "reflexo" de uma realidade a ser justificada, mas porque nela se encontra o mistério do trans-

8 BOFF, L. Saber cuidar - Ética do humano - compaixão pela terra. Petrópolis: Vozes, 1999. p. 73.

9 CAPRA, F. O tao da física. São Paulo: Cultrix, 1983. p. 103.

10 CASTIÑEIRA, À. A experiência de Deus na pós-modernidade. Petrópolis: Vozes, 1997. p. 180. 
cendente, onde os sem voz e sem vez encontram abrigo. Sua experiência diária de impotência se transforma em esperança, profecia e utopia. Sua vontade de Deus vai eliminando o ópio a que estão submetidos. Vai-se constituindo em protesto e poder das pessoas excluídas, como energia que as torna sujeitos da história, transformadoras da realidade. O próprio Jesus, conforme cita o evangelho segundo Lucas $(10,21)$, se alegrou com a experiência religiosa dos humildes: "Eu te louvo, ó Pai, porque revelaste estas coisas aos pequeninos...".

A violência continua sendo um dos problemas mais sérios da humanidade. Muitos dos conflitos no mundo, além de possuírem causas econômicas e políticas, também derivam da intolerância e de concepções religiosas fundamentalistas. O grande desafio das religiões, das escolas e demais instituições que visam contribuir com a educação da juventude, é promover uma cultura da tolerância, da paz e da solidariedade. Isso é condição sine qua non para a vida ser possível, pois, do contrário, sairão fortalecidos os fanatismos, radicalismos, proselitismos, nazismos...

\section{Formação de jovens ou de técnicos para o mercado?}

Já existe um consenso em torno da ideia de que o grande desafio da educação não é apenas o de tornar o jovem um técnico, um operário, um profissional, mas, especialmente, o de lhe proporcionar condições para a busca de uma educação que proporcione sentido para a existência humana e do universo, para um compromisso solidário e para o cuidado com a "Casa Comum". Nesta perspectiva, conforme sugere Jorge C. Ribeiro, a religiosidade é reconhecida como sendo uma energia humana, educável, e que pode ser uma poderosa aliada no processo educativo. Não é mais convincente e nem suficiente a procura apenas por "tecnologias" e por conhecimentos racionais, como sendo os únicos capazes de satisfazer as necessidades e desejos humanos. ${ }^{11}$

A tendência atual dos sistemas de ensino dirigidos segundo a lógica do mercado, especialmente imposta aos estudantes que frequentam escolas de ensino médio e de pós médio, nos cursos de formação técnica, é a de vir a adquirir certa competência profissional e se tornar um trabalhador, um funcionário de alguma empresa e receber um salário que lhe

11 RIBEIRO, J. C. Religiosidade jovem. São Paulo: Loyola/Olho d'água, 2009. p. 241. 
garanta a satisfação, ao menos, de suas necessidades básicas. Um curso técnico lhe garante informações e certos conhecimentos necessários para o exercício de uma profissão.

Todavia, o bom exercício de uma profissão não depende apenas de informações e conhecimentos. Os caminhos de realização humana dependem de uma formação integral, que considere outras dimensões tais como a intuição, a sensibilidade humana, a capacidade de diálogo e de socialização, o senso crítico, a criatividade e as dimensões da ética, da utopia, da religiosidade e do desenvolvimento psicoafetivo. Estas dimensões são tão ou mais importantes e necessárias que a capacidade de decorar fórmulas e frases, somar e multiplicar, responder perguntas previamente aprendidas, raciocinar, memorizar e escrever um texto dentro de uma certa metodologia científica. Sem considerar essas dimensões no processo de ensino-aprendizagem do jovem, ele terá grandes dificuldades de encontrar o sentido da existência humana e do universo.

Henri Joubrel ainda no início da segunda metade do século passado, oferecia uma equação entre desenvolvimento econômico e juventude que serve como um dos exemplos possíveis para essa questão. Ele comentou que

os Estados Unidos da América, o país mais rico e tecnicamente evoluído do mundo, é também o que apresenta cada ano, proporcionalmente ao número de habitantes, o maior número de criminosos, de alienados, de neuróticos, de inadaptados sociais de todos os gêneros e de delinquentes juvenis. ${ }^{12}$

Se isso é verdade, então não se pode afirmar que desenvolvimento econômico e qualidade de vida andam necessariamente juntos.

Os grandes temas das religiões mundiais, tais como, Deus, divindades e seus atributos, vida moral, alma, pluralismo religioso e mística, bem como as teorias antirreligiosas ou ateias, aglutinam elementos indispensáveis para a formação integral das crianças, adolescentes e jovens, pois são elementos referenciais da história e da cultura humana. Debatê-las, significa adentrar-se a elementos constitutivos das cosmovisões humanas; nestas se encontram os fundamentos sobre os quais foi-se

12 Apud. ALVES DE CAMPOS, A. A juventude e os seus problemas. Lisboa: União, 1961. p. 99. 
desenvolvendo a ciência; desta maneira elas são importantes para uma compreensão mais ampla do ser humano e do seu meio.

Conforme a lógica do mercado, tudo vira mercadoria, inclusive a educação. Todavia, a educação é um direito universal, ligado à própria condição humana e é, enquanto direito, que ela deve ser defendida. Ela é uma ferramenta indispensável nos processos de humanização, socialização e subjetivação. A integração entre estes processos se viabiliza na educação pela igualdade e pela justiça. Diante do atual processo de globalização do mundo, faz-se necessário uma educação integral e não apenas técnica, do contrário a educação não poderá ser um instrumento importante contra todas as formas de violência e degradação do ser humano, nem, tampouco, um caminho de promoção da paz e da sensibilidade solidária.

\section{A exclusão social no brasil desafia os jovens}

Por mais que o termo "exclusão" se pareça um tanto quanto ultrapassado, fetichizado, ou reducionista, e mesmo que essa categoria pudesse ser substituída por novas desigualdades ou situação subalterna, vulnerabilidade ou realidade dos situados à margem do processo, fato é que velhas e novas formas e processos de exclusão concorrem no cenário atual brasileiro. Existe um grande contingente de jovens sobrevivendo em uma conjuntura nada animadora. Por mais que se entendam capazes de uma ação coletiva transformadora e lutem incansavelmente enquanto sujeitos de uma realidade que lhes seja um pouco menos violenta e cruel, essa realidade sonhada tende a tornar-se fantasia ou ilusão. A esperança se transforma em desespero e, este, naquilo que se considera como efeito deletério de suas práticas: a violência, a revolta e a insubmissão. Sentem-se absolutamente excluídos de quase todas as portas de acesso aos bens materiais, culturais e simbólicos que a sociedade atual oferece. Os processos de exclusão, que afetam jovens brasileiros, geram suas vítimas por um ou mais desses critérios: cor, etnia, gênero, classe social, pertença religiosa, grau de escolaridade, ideologia política, local de residência, deficiência física ou mental e trabalho, entre outros.

O normal seria pensar que quanto mais ciência, tecnologia e educação, tanto maior a possibilidade de as pessoas terem acesso a uma alimentação farta, barata e sadia, mas o inverso vem sendo duplamente evidente. As políticas públicas de educação estão sendo minimizadas e, com ela, a qualidade de vida vem caindo. 
Ao longo do século XX, o Brasil manteve taxas de crescimento econômico entre as mais elevadas do mundo, porém, os indicadores sociais continuavam sempre entre os piores do mundo; também na questão da concentração de renda, o Brasil continuava entre as piores posições, segundo o Índice Gini. A identidade nacional, ou seja, o rosto do Brasil, durante grande parte do século XX, fora construído a partir de fatores como: mortalidade infantil, desarticulação e ineficiência do sistema educacional, crescente índice de doenças endêmicas, sucateamento da estrutura econômica, científica e tecnológica já montada, miséria crescente, dívida externa e interna acentuadas, violência generalizada, aviltamento da moeda, desorganização e/ou apropriação oligárquico-burguesa do Estado.

Os primeiros 15 anos do século XXI começou a mudar essa identidade nacional, apresentando certa elevação positiva no Índice de Desenvolvimento Humano, especialmente no que tange aos campos da educação e da saúde. Todavia, como se diz popularmente, alegria de pobre dura pouco. Nos últimos anos a sociedade brasileira, desgovernada, vem destruindo a intervenção do Estado no desenvolvimento socioeconômico, promovendo maior liberdade na economia, causando um consequente aumento da pobreza e da exclusão social. O Brasil volta a ser uma vergonha mundial, pois cresce a concentração de riquezas nas mãos de poucos, e o desemprego e a miséria para um número crescente e assustador de brasileiros. O Brasil volta a ser considerado uma das nações mais violentas e injustas. É o lugar do planeta onde mais cresce a diferença entre ricos e pobres.

A carta enciclica sobre $O$ trabalho humano, de João Paulo II, fala que "o direito de propriedade privada está subordinado ao direito de uso comum, subordinado à destinação universal dos bens". ${ }^{13}$ As aprendizagens e os bens espirituais e materiais de cada pessoa têm sempre uma dimensão social, pois são recebidas de outros e destinam-se aos outros. Ao refletir sobre o livro dos Atos dos Apóstolos $(20,35)$ pode-se perguntar: quando vamos aprender que só é feliz quem faz os outros felizes? Quem é solidário com os sofredores? Numa visão cristã, promover uma melhor distribuição de benefícios e renda não é apenas gesto de boa vontade, mas verdadeira restituição dos bens que se destinam a todas as pessoas, a começar pelos mais necessitados. A soberania, a

13 JOÃO PAULO II. Carta Encíclica Laborem Exercens. Sobre o trabalho humano. São Paulo: Paulinas, 1981. p. 51. 
independência, o combate a corrupção, a democracia e a inclusão social que o Brasil vinha conquistando no início deste século, agora voltam a ser jogadas no lixo da história. Também, o Papa Francisco, quando do Encontro Mundial de Movimentos Populares, em Roma, Vaticano nos dias 27-29 de outubro de 2014, em seu discurso afirmou que: "o amor pelos pobres está no centro do evangelho, a terra, casa e trabalho, aquilo pelo que os movimentos sociais lutam são direitos sagrados e exigi-los não é estranho a doutrina da Igreja, mas é justamente a sua essência". Junto dos movimentos populares ele disse: nenhuma família sem moradia, nenhum agricultor sem terra, nenhum trabalhador sem direitos, nenhuma pessoa sem a dignidade que o trabalho dá. ${ }^{14}$

Como nunca antes vistos, agora depredam-se os recursos naturais e se põe em risco a sobrevivência de um número crescente de pessoas. A cobiça está acima da fraternidade. A propriedade tem mais valor do que a vida. Até mesmo a Força Aérea Brasileira passou a ser usada para transportar drogas. As notícias mais recentes do The Intercept Brasil deixam claro que o Brasil vem sofrendo, nos últimos anos, um duro golpe jurídico, midiático e parlamentar, aparecendo como protagonistas do golpe os dirigentes da operação lava jato.

\section{A sensibilidade solidária e a sabedoria da realização humana}

A sociedade tecnológica prometeu o paraíso à humanidade. Afirmou que, com o progresso e a expansão do mercado, a humanidade entraria no paraíso. Para grande parte da humanidade o que recebeu, até hoje, além da possibilidade de sonhar, foi uma grande desilusão. Boa parte dela encontra-se absolutamente excluída dos benefícios oferecidos pela ciência e pela técnica. Exemplo disso é o atual governo neoliberal do Brasil que, ao mesmo tempo em que propõe a globalização da economia e um Estado mínimo, gera uma intensa dinâmica de desintegração, de destruição e desarticulação da esfera pública, que é o espaço onde deveriam ser garantidos os direitos sociais: saúde, moradia, educação, segurança e previdência. Todavia, o que se constata é o aumento da pobreza, do desemprego e da exclusão social para as grandes maiorias, e a expansão de um conjunto de relações sociais, marcadas pela corrupção

14 Disponível em: <https://www.conic.org.br/portal/files/2014/Encontro_Mundial_de_Movimentos_Populares_com_o_Papa_-_DocSntese.pdf>. Acesso em: 16 ago. 2019. 
generalizada e por um tecido social competitivo, individualista e não solidário. A qualidade total, defendida pela lógica do mercado, não coloca no centro a vida, em suas diferentes expressões, mas a eficiência, a eficácia, a produtividade e o lucro.

Desencantada com os resultados obtidos pela ciência, a humanidade está inquieta, diferentes grupos pendem para os fundamentalismos religiosos, mas em geral as pessoas continuam a se perguntar sobre Deus, sobre si mesmas e sobre o sentido da vida. E, porque não encontram, satisfatoriamente, as respostas, a insatisfação cresce. Por um lado, aparecem tendências humanas de "sair" do mundo ou negá-lo e, por outro, emerge uma nova sensibilidade, uma mística da solidariedade.

Jung Mo Sung acredita que vale a pena continuar insistindo na importância da teologia. Ele diz:

acho que continuo a fazer teologia por causa dos rostos das crianças pobres coladas ao portão esperando por pessoas que as possam amar gratuitamente e se preocupar com os seus problemas e ajudá-las a superarem ou diminuírem os seus sofrimentos. ${ }^{15}$

É nesse sentido que emerge o valor da perspectiva religiosa, também em tempos de pós-modernidade, onde não se pretende abranger e nem possibilitar tudo, mas abrir e proporcionar um "mais" em termos de vida humana. A religião, como qualquer realidade humana comporta contradições. Por um lado, ela vem sendo manipulada pelo mercado, pela idolatria do dinheiro, mas, por outro, ela consegue transmitir uma dimensão mais profunda, um horizonte interpretativo mais abrangente face à falta de sentido. Ela consegue também transmitir um sentido de vida último ante à morte: sentido de onde vem e para onde vai a existência humana. A religião consegue garantir os valores mais elevados, as normas mais incondicionais, as motivações mais profundas e os ideais mais elevados.

O ser humano, e mais fortemente os jovens, vendo-se limitados, sofridos e insatisfeitos, abrem-se para algo mais, para um elã vital que os levam a enfrentar obstáculos, a alcançar seus propósitos e a sonhar. Esse elã está neles, mas é maior do que eles. Não está em seu poder manipulá-lo, criá-lo ou destruí-lo. É a experiência religiosa e são os processos educacionais que, por sua vez, deveriam implicar uma ruptura de nível

15 MO SUNG, J. Sujeito e sociedades complexas. Petrópolis: Vozes, 2002. p. 40. 
ontológico, uma separação radical do círculo das experiências habituais intramundanas, que nos introduz a uma realidade totalmente diferente que é o âmbito do mistério, do ideal, do transcendente, do sagrado. A busca dessa outra realidade não deve ser estranha à educação da juventude, pois, tal como sugere Hugo Assmann, educar significa defender vidas, e,

a educação se confronta com essa apaixonante tarefa: formar seres humanos para os quais a criatividade e a ternura sejam necessidades vivenciais e elementos definidores dos sonhos de felicidade individual e social. ${ }^{16}$

Assmann insiste na importância de sonharmos com um mundo onde caibam todos, onde caibam também muitos mundos. Para ele, o sonho de uma sociedade onde caibam todos, não deve ser mero devaneio teórico, faz-se necessário começar pela compreensão do ser humano. Ele acredita que

Doravante só será possivel sonhar com uma sociedade onde caibam todos se também nossos modos de conhecer conduzirem a uma visão do mundo na qual caibam muitos mundos do conhecimento e do comportamento. A educação se confronte com essa apaixonante tarefa de formar seres humanos para os quais a criatividade, a ternura e a solidariedade sejam, ao mesmo tempo, desejo e necessidade. [...] O ser humano 'funciona' melhor, a sós e em convivialidade social, com altas doses de euforia e discretas doses de cobrança à consciência. Por isso mesmo, é obra de suma delicadeza sensibilizar seres humanos para metas solidárias, por que não se trata de criar 'consciência' num sentido racionalista, mas de desencadear processos auto organizativos - cognitivos e vitais - em direção a um mundo mais solidário, respeitando e tomando como condições iniciais os processos auto organizativos atualmente existentes. ${ }^{17}$

Lembra Júlio H. de Santa Ana que as tradições religiosas, quando falam do "seu" Deus ou quando falam de um Deus "sem barreiras" normalmente afirmam que "o que Deus procura concretizar é a unidade de todo o seu povo: superar as divisões, derrubar as barreiras, abrir canais de compreensão e diálogo entre todas as nações e entre todos os grupos sociais" ${ }^{18}$, por isso, é necessário compreender o que separa os seres humanos. Só a partir da tomada de consciência dessas separações e das

16 ASSMANN, H. Reencantar a educação. 5..ed. Petrópolis: Vozes, 2001. p. 29.

17 ASSMANN, 2001, p. 67.

18 SANTAANA, J. de. Ecumenismo e Libertação. Petrópolis: Vozes, p. 8. 
causas que estão em sua raiz é que será possível visualizar quais são os caminhos apropriados para a unidade, para a superação das divisões, sejam elas, políticas, econômicas, geográficas, sociais, raciais, de gênero ou religiosas. Para isso é preciso começar pelo reconhecimento e pela compreensão do outro.

A realização pessoal passa não somente pela competência técnica e profissional, mas, também, pela compreensão e sensibilidade emocional, relacional e solidária. Não basta à universidade oferecer informações e conhecimentos. Ela é chamada a fomentar e a garantir processos de emancipação humana e busca de sabedoria. Educar para a esperança e a solidariedade é o caminho que leva à sabedoria. Segundo Jung Mo Sung,

uma sabedoria que está precisando ser ensinada e aprendida em todo o mundo é a que nos ensina que não se pode ser feliz e amar a si próprio de verdade se não se é capaz de se abrir ao sofrimento de outras pessoas, se não se é capaz de ter uma sensibilidade solidária. ${ }^{19}$

É recente o debate e o paradigma que procuram aproximar as dimensões da busca de sabedoria, competência, esperança e sensibilidade solidária nos processos educacionais. A Teologia da Libertação é uma das iniciativas que sempre procurou abrir as portas dessa aproximação, colocando como critério e julgamento do avanço das ciências, as súplicas dos pobres e sofredores. Especialmente diante das diferentes formas de exclusão, de miséria e fome, esses elementos passaram a ser essenciais para a educação. Jung Mo Sung questiona:

em que o conhecimento da dimensão religiosa dos seres humanos e das sociedades podem nos ajudar na compreensão da nossa sociedade, da nossa cultura, e nas necessárias modificações para que possamos pelo menos, em curto prazo, diminuir o número de excluídos/as? ${ }^{20}$

É nesse mesmo sentido que Assmann considera a educação para a solidariedade como a mais avançada tarefa social emancipatória, e percebe que ela, diante da falta de políticas públicas, econômicas e sociais orientadas para salvar todas as vidas humanas existentes, tem "um papel determinante na criação da sensibilidade social necessária para reorientar a humanidade". ${ }^{21}$

\footnotetext{
19 MO SUNG, 2002, p. 172.

20 MO SUNG, 2002, p. 172.

21 ASSMANN, 2001, p. 26.
} 
Educar significa buscar e transmitir sabedoria. E a sabedoria nasce ou se constrói num processo de solidariedade. A educação passa por duas forças conflitantes e antagônicas. Uma é a ciência, aquela que faz do ser humano um buscador de conhecimentos, que o torna indivíduo inteligente, capaz de manejar máquinas sofisticadas, de compreender sistemas complexos, de saber construir edifícios, conhecer algumas características da lua, do sol e dos milhões de seres que habitam a terra e as águas. Ela ajuda a identificar e descrever o tempo e o espaço, coisificar tudo o que se pode manipular, objetificar tudo o que se busca saber, definir, enumerar e classificar, assim, o ser humano aprende a inventar e escrever textos e também prever resultados de certas ações. Outra é a sabedoria que vai além da ciência, pois contempla o mistério, o ocaso e a imprevisibilidade. Não é algo que pode ser transmitido e aprendido de forma vertical, isto é, de alguns "para" os demais. Ela brota da ação solidária e da compreensão e participação do sofrimento do outro. Ela não pode ser claramente definida através de conceitos e teorias racionais, pois passa essencialmente pela gratuidade, pelo sofrimento, pelo prazer, pelo Sensus Fidei, pela sensibilidade solidária e pelo relacionamento amoroso. Ela é mais um sentir, uma intuição cheia de fé que penetra no mais profundo de cada ser humano e se faz nele a sua mestra e educadora, ao ponto de torná-lo capaz de salvar vidas. Edgar Morin diz que é a partir da compreensão que se pode lutar contra o ódio e a exclusão. Para ele, ensinar a viver é transformar conhecimento em sabedoria:

Ensinar a viver necessita não só dos conhecimentos, mas também da transformação, em seu próprio ser mental, do conhecimento adquirido em sapiência, e da incorporação dessa sapiência para toda a vida. [...] A compreensão humana nos chega quando sentimos e concebemos os humanos como sujeitos; ela nos torna abertos a seus sofrimentos e suas alegrias. ${ }^{22}$

\section{Conclusão}

Quem procura estar atento à religiosidade da juventude logo percebe que ela faz parte da própria aposta da juventude em prol da sua própria saúde, do seu processo de formação e educação, da sua luta por políticas públicas e da construção de uma nova sociedade. A juventude que luta por uma sociedade sem classes já compreende que não é somente uma luta dos, mas também das jovens e mulheres. A mulher é aquela

$\overline{22}$ MORIN, 2000, p. 47 $; 51$. 
parcela da sociedade que preserva a sociedade, em todos os sentidos, da alienação, abrindo-lhes, contra o "fim da história", as portas da esperança.

O Papa Francisco, na sua Exortação Apostólica, Para os jovens e para todo o povo de Deus, insiste na importância de uma Pastoral Juvenil Popular, que seja capaz de

criar espaços inclusivos, onde haja lugar para todos os tipos de jovens e onde realmente se manifeste que somos uma Igreja de portas abertas. [...] Precisamos de uma Pastoral Juvenil Popular que abra portas e ofereça espaço para todos e para cada um com suas dúvidas, seus traumas, seus problemas e sua busca de identidade, seus erros, sua história, suas experiências do pecado e todas as suas dificuldades. ${ }^{23}$

Para o Papa Francisco "a Pastoral Juvenil, quando deixa de ser elitista e aceita ser 'popular', é um processo lento, respeitoso, paciente, esperançoso, incansável, compassivo." Para ele, esta deve sempre ser uma pastoral missionária. ${ }^{24}$

Ao que tudo indica, a sociedade não vive apenas numa época de mudanças e, sim, numa mudança de época, pelo fato de, hoje em dia, existir a possibilidade de viver de diferentes maneiras, de pensar livremente, de conservar a vida e de adaptar-se ao meio ambiente de maneiras nunca vistas antes, de satisfazer necessidades e realizar desejos como nunca, mesmo assim o que permanece para todo o sempre é o esforço para minimizar o sofrimento e para encontrar mais alegria e felicidade.

É nesse sentido que podemos concluir com de uma reflexão sobre o que é "viver a vida" de Otto Maduro. Ele afirma que

Viver a vida é entre outras coisas, buscar a vida feliz e não meramente sobreviver. Não se resume numa simples luta contra a morte, mas é busca do prazer em comum, a alegria duradoura, o deleite profundo, o gozo gratuito, a felicidade que contagia; é desfrute compartilhado do afeto, da companhia, do trabalho, do alimento, do descanso, da arte, do jogo, da dança [...] enfim, da festa! É também a aptidão para assumir criativamente o sofrimento pessoal como dimensão intrínseca da própria vida, disposição para apreciar e acompanhar a aflição do

${ }^{23}$ FRANCISCO. Exortação apostólica pós-sinodal: Christus Vivit. São Paulo: Paulus, 2019. n. 234.

24 FRANCISCO, 2019, n. 236; 240. 
outro com solidariedade e ternura. Mas, a vida boa é, também, esforço para superar o sofrimento injusto e evitar o sofrimento desnecessário. ${ }^{25}$

\section{Referências}

ALVES DE CAMPOS, A. A juventude e os seus problemas. Lisboa: União, 1961.

ASSMANN, H. Reencantar a educação. 5. ed. Petrópolis: Vozes, 2001. BOFF, L. Saber cuidar - Ética do humano - compaixão pela terra. Petrópolis: Vozes, 1999.

CAPRA, F. O tao da física. São Paulo: Cultrix, 1983.

CASTIÑEIRA, À. A experiência de Deus na pós-modernidade. Petrópolis: Vozes, 1997.

CONIC. Encontro Mundial de Movimentos Populares com o Papa. Documento Síntese. Disponível em: <https://www.conic.org.br/portal/ files/2014/Encontro_Mundial_de_Movimentos_Populares_com_o_ Papa_-_DocSntese.pdf $>$.

DAYRELL, J. Múltiplos olhares sobre educação e cultura. Belo Horizonte: UFMG, 1996.

DREIFUSS, René A. A época das perplexidades. 2. ed. Petrópolis: Vozes, 1997.

FOUCAULT, M. Microfisica do poder. 5. ed. Rio de Janeiro: Graal, 1985.

FRANCISCO. Exortação apostólica pós-sinodal Christus Vivit: Para os jovens e para todo o povo de Deus. São Paulo: Paulus, 2019.

. Exortação apostólica Gaudete et Exsultate: Sobre a chamada à santidade no mundo atual. Doc. Pontifícios 33. Brasília: CNBB, 2018.

JOÃO PAULO II. Carta Encíclica Laborem Exercens. Sobre o trabalho humano. São Paulo: Paulinas, 1981.

KUHN, Thomas S. A Estrutura das Revoluções Científicas. São Paulo: Perspectiva, 1962.

25 MADURO, O. Mapas para a festa, Petrópolis: Vozes, 1994. p. 30. 
MADURO, O. Mapas para a festa: reflexões latino-americanas sobre a crise e o conhecimento. Petrópolis: Vozes, 1994.

MATZA, D. As tradições ocultas da juventude. In: BRITTO, S. (Org.). Sociologia da Juventude III: a vida coletiva juvenil. Rio de Janeiro: Zahar, 1968.

MO SUNG, J. Sujeito e sociedades complexas, para repensar os horizontes utópicos. Petrópolis: Vozes, 2002.

MORIN, E. A cabeça bem-feita: repensar a reforma, reformar o pensamento. Rio de Janeiro: Bertrand Brasil, 2000.

RIBEIRO, J. C. Religiosidade jovem, pesquisa entre universitários. São Paulo: Loyola; Olho d'agua, 2009.

SANTA ANA, Júlio de. Ecumenismo e Libertação. Petrópolis: Vozes, 1987.

SERNA, L. Globalización y participación juvenil. In: Jóvenes. Rev. Est. Juventud. México: 1998. 